\title{
The Libraries in Senior High Schools and Vocational Schools Faced with Knowledge-based Economy
}

\author{
Pei-lang Chen \\ Director of Library \\ WEN-HUA senior high school \\ Taichung Taiwan
}

\begin{abstract}
It is the age of technology revolution and is what is called the age of "third wave." Knowledge has become the most precious resource and property of a person or an organization. As globalization is a trend, knowledge becomes extremely significant. All the educational institutions also need to do well in knowledge management. In this age of information explosion and information technology, a single school, especially the school library, faces the biggest influence and impact. Besides, librarians themselves are the managers of knowledge, and they stand at the frontline to put knowledge management into practice in school. Therefore, according to knowledge-based economy, this article probes into the possible ways to operate the libraries in senior high schools and vocational schools when faced with and information knowledge exploded globally.
\end{abstract}

\section{Introduction}

"Knowledge brings wealth." It is an ancient Chinese proverb used to encourage students to study hard. Nowadays, it can also be used to exactly describe the epoch of knowledge-based economy. It is an epoch of technological revolution; that is, the Third Wave. (Toffler, 1980) Knowledge becomes the resource or asset one or an organization treasures most.

With the intense global competition brought about by knowledge-based economy, either non-profit organizations or governmental institutions require management and innovation much more than commercial organizations. In this era of information explosion, schools, especially the school libraries, are faced with the greatest shock and influence. Moreover, librarians themselves are the managers of knowledge, not to mention the frontline staff in charge of the actualization in school. As institutions for brain cultivation, schools must take action to develop the library fitting in with the aspects of knowledge-based economy. 


\section{Meanings and Core Factors of Knowledge-based Economy}

\section{A. Meanings of Knowledge-based Economy}

From Drucker's viewpoint, knowledge plays a very important role in the process of social evolution. As far as its essence is concerned, knowledge is the professional realization of the possessor on a specific filed. (Drucker, 1993) As to the "knowledge" for knowledge management, generally speaking, it contains four concepts: data, information, knowledge and wisdom. The concepts mentioned above are overall called "knowledge assets." OECD (Organization for Economy Co-operation and Development) categorizes knowledge into four types: know-what, know-why, know-how and know-who. (OECD, 1996) Therefore, education industry is one of the knowledge assets, where the library plays a vital part.

According to Taiwan's official statement, knowledge-based economy is the economy based on the inspiration, diffuseness and application of knowledge as well as information. It creates and makes the best of the power and efficacy of knowledge. In addition, it is the motive force to maintain the consecutive economic expansion, superior to traditional factors of production, such as land, capital, etc. (Council for Economic Planning and Development, 2000) As a consequence, knowledge is the major motive force to accelerate development, to create wealth, and to provide working opportunities. (Wu, Ching-san \& Lin, Tien-yo, 2000)

\section{B. Core Factors of Knowledge-based Economy}

As for the management of a library, there are three main core factors when the library is faced with knowledge-based economy. The first one is knowledge management; the second, information technology and the third, innovation.

\section{Knowledge Management}

Knowledge management is the economy based on knowledge; one of the most obvious characteristics is to improve knowledge management. With knowledge management, knowledge enterprise develops an effective knowledge system, which makes the knowledge of an organization efficiently created, circulated and value-added.

Arthur Andersen Business Consulting in Japan puts forward the knowledge management equation: $\mathrm{KM}=(\mathrm{P}+\mathrm{K}) \mathrm{s} . \mathrm{KM}$ is for "knowledge management", $\mathrm{P}$ is for "people", + is for "technology", $\mathrm{K}$ is for "knowledge", and $\mathrm{S}$ is for "share". As a result, knowledge management can increase the quality and quantity of creative knowledge in an organization, and meanwhile strengthen the feasible value of knowledge. This equation simply and clearly illustrates the importance of knowledge management to the development of an organization.

\section{Information Technology}

Knowledge-based economy is the product responding to the trend of 
informationization. (Graham, 1999) The 21st century is the epoch of information technology. The invention of Internet particularly has a massive influence on human society with its omnipresent feature. Information technology changes the production, dissemination, deposition and acquisition of knowledge, transforms the ways human communicates and interacts, and also affects the quality and evolution of a culture. It is not only the basis of knowledge management but the significant fundamental element for knowledge-based economy.

\section{Innovation}

In the end of the 21 st century, the movement of knowledge management arose, right after the "quality movement" in 1980s and the "process reengineering" in 1990s. It turns into the latest focus with weighty importance. The goal of knowledge management lies in "growth", whose key point is innovation. The motive force to the growth of an organization comes from innovation stimulated by knowledge.

Innovation includes the one for knowledge, management, skills, systems, and organization structure. In consequence, innovation is the motive force to boost knowledge-based economy. Only when an organization continually innovates can it deal with high-speed changes in this epoch.

\section{Current Libraries in High Schools and Vocational Schools}

High school is the linking education between compulsory and universities education, which is also the preparation education for universities. Accordingly, the high school in Taiwan is supposed to be open, multiple and vivacious. Nevertheless, under the pressure from the doctrine to enter a higher school, it is especially difficult for the culture and fracture of high school education to make a breakthrough. In terms of the libraries in high schools and vocational schools, the current circumstances are as follows.

\section{A. Lack of Hardware Facilities}

Except for some newly-instituted high schools whose libraries have their own buildings with perfect structure and surroundings, the libraries in most high schools and vocational schools are of poor facilities and surroundings, usually with less space. Many school libraries are even adapted from classrooms or buildings built for other purposes whose structure or plans of routes might not be ideal.

\section{B. Less Personnel with Full-Time Positions}

In the past, the personnel of the libraries in national high schools and vocational schools contain one to three staffs, including the curator, an assistant and a school worker. After the year of 2003, though a section director has been added to the personnel in many libraries, the present 
head account of faculty does not fit in with the need in the present or for future development. Some libraries only have one staff, making it difficult to fully exploit their functions.

\section{Less Collection}

Due to the limit of surroundings and budget, the collection of the libraries in high schools and vocational schools are usually not in abundance. Based on the statistics, the average number of books in Taiwan's libraries in high schools and vocational schools is 28,610. Generally speaking, the number in the libraries in national high schools and vocational schools is 33,737, while in private schools, the average number is 20,921. (Shiaw, Chien-hua, 2006)

\section{Low Usage Rate}

High schools are different from universities because high school students do not possess enough spare time. In many schools, early studies and after-school classes are required so that students barely have time to read books in the library. Besides, teachers do not ask students to write reports with the pressure from the universities entrance exam, lowering the chances for students to look for academic information. Instead, most students borrow from relaxing collection (including novels, essays, journals, movies or music). As a whole, the usage rate is low. As to teachers, they often make use of the libraries in universities for further study or to read the academic articles. Some of them borrow books from the school library according to their need or what collection the library owns.

\section{E. Improper Duty for the Director}

Since January, 2003, many schools have instituted the Information \& Media Section. However, its goal is not to provide service and assistance for the collection, production, storage, and dissemination of information and media, such as teaching media and resources of movies and music, but to maintain both the software and hardware for all the information facilities in the school. Most of its work overlaps that of the Equipment Section of the Office of Academic Affairs so that it is hard to distinguish the duty of these two sections. (Chen, Pei-lang, 2006) The Information \& Media Section has to deal with a lot of workload while most of the duty is improper. It works as a section totally independent of the library and its function completely deviates from the original scheme.

\section{Directions of Management for Libraries in High Schools and Vocational Schools}

Faced with the epoch of knowledge-based economy, libraries in high schools and vocational schools must meet the transformation in the future with fresh ways of thinking in order not to fall behind, or even to be eliminated. Based on three core factors related with knowledge-based economy-knowledge management, information technology and innovation-I, therefore, bring up some directions of management for libraries in high schools and vocational schools. 


\section{A. Focusing on the Collection of Language and Literature}

With limited space and budget, libraries in high schools cannot, as the libraries in universities can, meet most people's need. Thus, the collection of libraries in high schools should exploit the most economic asset instead of paying too much attention to the number of the collection. To put it simply, never add to the collection just to increase the figure. If anything is added to the collection at random, but the usage rate is relatively low, it is a waste of resources. As a matter of fact, most readers in the libraries in high schools and vocational schools borrow books on language and literature, especially the relaxing ones. Every school should purchase what fits its own distinguishing features to boost the usage rate to its fullest.

\section{B. Purchasing Electronic Data}

In the era of information technology, much paper data begins to be digitized into electronic books, electronic journals, electronic database, etc. Unlike the university libraries, high school libraries cannot afford to purchase expensive and gigantic database. However, less expensive electronic journals and electronic database can be gradually developed.

\section{Collaborating with Universities Nearby}

Recently, more and more students involve themselves in many kinds of research. If, in the near future, high school education can be implemented much more "normally", then students will require much more academic information for their research. But in terms of the present software and hardware of libraries in high schools and vocational schools, it may be hard to meet students' need. Thus, high schools can collaborate with universities nearby so that students will be able to borrow books from university libraries after school; they will even be able to consult the electronic database at home. In this way, the resources in the university libraries will not only be used to the fullest, but with the budget from high schools with which those universities collaborate, they will also expand their resources and service. With the positive interchange, the university libraries will become the resource center for high schools nearby, which benefits both sides.

\section{Improving the Specialty of Librarians}

Faced with the epoch of knowledge-based economy, librarians ought to be transformed into those with sufficient specialty to fit in with the technological transition. With more and more digitized collection, they are supposed to acquire the knowledge on information technology, so that they can easily manage digital data, electronic resources and media data, making the libraries the future "digital libraries."

\section{E. Allocating Proper Duty to the Director of Information \& Media Section}

As what is mentioned above, most directors of Information \& Media Section do not have proper duty. "Information" is not equal to "computers" at all. If libraries strive to implement 
knowledge management, then proper duty should be allocated to the director of Information \& Media Section. They should focus on the management of digital data, electronic resources and media information, helping the learning of students, teaching of teachers and administration of a school. Only in this way will they handle the challenge in the 21 st century. If the directors are busying fixing the hardware, schools will definitely miss the boat on the competition, as a proverb goes, "Save a little, lost a lot."

\section{Conclusion}

Knowledge-based economy is the trend in the present. As institutions for brain cultivation, schools must develop the very library corresponding to this trend. Knowledge is the motive force of service. If the concept of knowledge management is hammered into an organization, the database meeting customers' need is developed, and the whole staff can renew the database and exchange knowledge according to the feedback of customers and their actual needs, not only will the knowledge be fresh all the time, but new knowledge will be accumulated and created so as to fulfill the goal of prioritizing customer satisfaction. (Lin, Hai-chin, 2002)

Faced with the epoch of knowledge-based economy, schools play a far more significant role. As a result, school libraries have to keep adjusting and growing to cope with the challenge caused by knowledge-based economy. High school libraries are the essential logistical department providing knowledge; yet they do not possess enough space together with staff. In order to survive in the trend of information revolution and knowledge management, libraries in high schools and vocational schools should select the paper collection with caution, broaden the electronic database and collaborate with libraries in the universities, so that the function will be exploited to the fullest. Then the tiny but delicate libraries with full functions shall be formed.

\section{References}

Cheng, Pei-lang (2006). Problems And Innovation of National Senior High School Organization .The Wen-hua Educational Newspaper, 14, 15-19

Council for Economic Planning And Development (2000). Plans for Development of Knowledge-based Economy .89,08,30.

Davenport, T. H. \& Prusak, L. ( 1998 ). Working knowledge : how organizations manage what they know. Boston : Harvard Business School Press.

Drucker, P. F. ( 1993 ) .Post-capitalist Society. New York : Harper Business.

Duffy, J ( 1999). Harvesting experience : Reaping the benefits of knowledge. Prairie Village, Kansas : ARMA International. 
Fu, Zhen-kun (Translator) (1994). Post-capitalist Society .by Drucker, P.F. Taipei : Shi Bao Publisher.

Ganguly, A. (1999) . Business-driven research \& development. West Lafayette, Indiana : Ichor Business Books.

Lin, Hai-qing (2002). Knowledge Management And Education Development. Taipei : Yuan Zhao Publisher.

Liu, Jing-hua (Translator) (2001). The First Book of Knowledge Management. by Arthur Andersen, Taipei : Weekly Magazine of Business.

Newman, J. H. ( 1987 ). The Idea of a University. Chicago : Loyala University Press.

OECD ( 1996 ). The knowledge-based economy report. Paris : Author.

Rastogi, P.N. (2000). Knowledge management and intellectual capital--the new virtuous reality of competitiveness. Human systems management,19 ( 1 ) ,39-49.

Rosenberg, M. J. ( 2001 ) .E-Learning: Strategies for Delivering Knowledge in the Digital Age. New York :McGraw-Hill.

Shiaw, Chien-hua (2006) .Survey of Libraries Nowadays. The introduction of work reviewing meeting of senior high library council in 2006.

Toffler, A. ( 1980 ). The Third Wave. New York : Morrow.

Wang, Ru-Zhe (2002). The Application And Theory of Knowledge Management : Take Educational Field And Its Innovation for Example. Taipei : Wu Nan Publisher.

Wu, Ching-san \& Tien-yo, Lin (2000).The Knowledge-based Economy. Educational Data And Research,37, 100.

Zhang, Yu-wen (Translator) (2000) .Harvard Business Review on Knowledge Management . by Drucker, P.F. Tian Xia Publisher, Taipei 